\title{
Ohiko eta ezohiko maratoien erronka. Irabaziko ahal dugu!
}

\author{
The challenge of the usual and extraordinary marathons. Will we win? \\ Haritz Esnal Amundarain*, Nerea Sarriegi Gorrotxategi*, Maria Reyes Rodríguez Rivera², \\ Ricardo Palenzuela Arocena', Maite Urcelay Olabarria', Felix Zubia Olascoaga ${ }^{3}$ \\ ${ }^{1}$ Donostia Unibertsitate Ospitaleko Larrialdi Zerbitzuko medikua \\ ${ }^{2}$ Osasun Larrialdietako teknikaria \\ ${ }^{3}$ Donostiako Unibertsitate Ospitaleko Zainketa Intentsiboko Unitateko medikua \\ haritz.esnalamundarain@osakidetza.eus;nerea.sarriegigorrotxategi@osakidetza.eus.
}

\section{Laburpena}

Ultramaratoia maratoia baino luzeagoa den lasterketari deitzen zaio. Gaur egun lasterketa mota hauek gorakada handia izan dutenez, osasunean izan ditzaketen ondorioak aztertzeko helburuarekin artikulu hau idaztea pentsatu dugu, alde batetik, bibliografiak zer dioen ikusiz, eta, bestetik, 2017. urtean antolatu zen Ehunmilak lasterketa-multzoan egindako artatzeak aztertuz. Uptodate erabiliz, bilaketa egin dugu kirolaren inguruan dauden gaixotasunei buruz eta multzoka aztertu eta ondo xehatu ditugu. Datu-bilketa 2017. urteko uztailaren 7tik 9ra egin zen Ehunmilak lasterketa multzoan Gurutze Gorriak bildutako artatze-datuetatik egin dugu. Bibliografia eta datuak aztertuz, garbi ikusten da gaitz ohikoenak arinak diren azaleko asaldurak direla (babak gehiengoetan), zaintiratu eta lesio muskularrak ere ohikoak izanik. Dena den, badira ere larriagoak diren gertaerak eta horien aurrean prest egotea gomendagarria da, maila egokiko antolakuntza-sistema bat eraikiz.

Gako-hitzak: kirolariak, kirol-lesioak, kirol-medikuntza, babes-gailuak

\section{Abstract}

Races so called Ultramarathon are those longer than a marathon. Nowadays these kinds of races are becoming more usual than they were some years ago. We have written this paper in order to learn about the consecuences of such long races on the health of the athletes. As a first step we review available bibliography on this topic. At the same time we performed a review about medical events registred during the Ehunmilak ultramarathon $2017^{\text {th }}$. Using the cientific knowledge platform Uptodate, we have done a research about illnesses related to sport practice, followed by a detailed classification of those diseases in different categories. We use medical assistance data collected by Gurutze Gorria between 7 and 9 of July of 2017 to build our data base. Once bibliography and data were reviewed, we concluded that most common sport practice related illnesses are light skin disorders (blisters mostly), and that sprains and muscular injuryes are also commonly finded. However, there are some more serious events and it is advisable to be prepared, building a high level organization system.

Keywords: athletes, athletic injuries, sport medicine, protective devices 
Bidalia: 2019ko apirilaren 30ean.

Onartua: 2019ko urriaren 16an.

http://doi.org/10.26876/osagaiz.2.2019.254

\section{Sarrera}

"Nenikhamen": irabazi egin dugu. Hori esanda hil zen Filipides mezularia, erabat akituta, Maraton eta Atenas arteko ibilbidea lasterka egin ondoren. Alegia, greziarrek irabazi zutela persiarren aurkako bataila. Mezu erabakigarri horren berri ematea izan zuen azken egitekoa. Garaiz iritsi ezean, Atenasko hiria erre eta bertako haurrak hilko zituzten greziarrek berek. Etsaiei ezer utzi baino nahiago zuten halako neurri latzak hartzea.

Ibilbide hura berbera errepikatu zuten maratoilariek 1896an, lehen Olinpiar Joko modernoetan. Hamabi urte geroago, 1908an, Londresen, antolatzaileek moldatu egin zuten luzera, Windsor gaztelutik pasaraziz. Geroztik, 42.195 metro ditu maratoiak. Hasieran, hil ala biziko ekintza izan zen; gaur, kirola da. Edozein kirolarirentzat erronka garrantzitsua da halako distantzia burutzea. Baina baita antolatzaile, mediku, tekniko eta boluntarioentzat ere beren lanak ondo egitea.

Ultramaratoia deitzen zaio maratoia baino luzeagoa den lasterketari. Hiru Haundiak izango da, noski, Euskal Herriko lehen ultramaratoia. Gasteizko Manuel Iradier mendi-elkarteak antolatu zuen lehen aldiz, 1987an, Gorbeia, Anboto eta Aizkorri batzen dituen mendi-proba. Zer iruditzen zaizue mendiz 100 kilometroko ibilbidea antolatzen badugu? Zer hobeto, izan ere, euskal herritarrok hain barneratua dugun mendizaletasuna eta erronkei aurre egiteko grina asetzeko?

Ondoren etorri ziren zenbait mendi-lasterketa; besteak beste, Zegama Aizkorri mendi-maratoia, mundu-mailan ezagunenetakoa; eta, 2010az geroztik, Beasaingo Ehunmilak lasterketa multzoa, aurten 10. ediziora iritsi dena.

Gaur egun, gorakada handia izan dute lasterketek: ultratrail lasterketak, mendi-maratoiak... Horietan, gero eta partaide gehiagok eramaten dute bere gorputza muturreko egoeretara $(1,2)$.

Idatzi honen asmoa da iraupen luzeko lasterketek osasunean izan ditzaketen ondorioak aztertzea. Hasteko, orain arteko bibliografiak zer dioen jasotzen du. Eta, ondoren, Ehunmilak Ultra-Traileko korrikalarien artatze-datuak aztertzen ditu; horretarako, 2017ko datu-bilketa baliatuko dugu.

\section{Kirolak eragindako gaixotasunak, bilaketa bibliografikoa}

Asistentzia medikoaren aldetik, ezaugarri bereziak dituzte urtratrail lasterketek. Lehenik, kirolariek gorputza behartzen duten bezala behartzegatik. Eta, horrez gain, lasterketak izaten diren inguruneagatik (3). Izan ere, askotan zaila da leku horietara behar den baliabidez iristea (irisgarritasun murritza dute); eta gainera, esparru geografiko handia hartzen dutenez, kontuan izan behar da zer eragin duten eguraldi txarrek eta ingurumeneko arrisku handiek.

Lasterketa mota hauetako parte-hartzea handituz doan neurrian, gero eta handiagoa da gertaera larriak izateko arriskua. Hala ere, literatura gutxi dago ekitaldi horietako asistentzia medikoaren antolakuntzari buruz. Ez dago adostasunik behar diren gutxieneko mediku-zerbitzuen inguruan, eta lasterketa motaren arabera hartu behar izaten dira erabakiak.

Dena den, ariketa fisikoak, datuek argi erakusten dutenez, onura gehiago ditu ondorio txarrak baino (4). Baina ondorio kaltegarriak ere badituenez, merezi du jakitea zehatz-mehatz zein diren. Oro har ez dira larriak izaten, baina bai kontuan hartu beharrekoak.

Badira zenbait aldagai kirolarien artean gertatzen direnak eta ezohikoak direnak gizartean (5). Aldagai horiek, izan ere, kirolaren eraginez sortutako egokitzapen fisiologikoaren ondorio dira eta 
batzuetan gaizki-ulertuak sor ditzakete, horiek interpretatzean. Gaizki-ulertu horiek ahal dela saihesteko, atsedenean egindako elektrokardiograma [EKG] eskatzen zaie kirolari guztiei, EHM-G2HMMM lasterketen aurretik. Komeni baita ezagutzea gorputz bakoitzaren egokitzapenak. Aurrerago aipatuko ditugu.

Hona hemen, aparatuz aparatu, zein diren gaixotasun garrantzitsuenak eta kirolarien artean jakinmin handiena sortzen dutenak.

\subsection{Gertaera kardiobaskularrak}

Bihotzeko gaitzek ematen diete kirolariei eta osasun-langileei beldurrik handiena; batez ere, heriotza eragin dezaketenak.

Bat-bateko heriotza. Adin ertaineko pertsonei gertatu ahal zaie, gertatu aurretik ezezaguna den kardiopatia batengatik. Honela definitzen da: aurreko 24 orduetan osasuntsu zegoen pazientearen heriotza, sintomak hasi eta ordubetera gertatzen dena (6).

Intzidentzia oso txikia du lasterketetan, biztanleria sedentarioan baino baxuagoa. Esan daiteke, beraz, ariketa fisikoa faktore babeslea dela bat-bateko heriotzarekiko. Intzidentzia-datuak aldatu egiten dira ikerketa batetik bestera, baita lasterketa motaren eta ariketaren intentsitatearen arabera ere. Maratoi-erdietan eta maratoietan, horrelako heriotza bat gertatu ohi da 57.000 / 259.000 partaideko; triatloietan, bat 52.630 partaideko $(7,8,9)$.

Arritmia gaiztoak dira heriotza horien kausarik ohikoenak: bentrikuluko takikardia eta bentrikuluko fibrilazioa (10). Beraz, oso garrantzi handia du berehalako berpizteak, batez ere desfibrilagailu automatikoaren erabilera azkarrak; izan ere, biziraupen-tasa \% 7-10 artean jaisten du minutu bakoitzeko atzerapenak (11). Lehen minutu horietan, ezinbestekoa da eskura izatea pazientearengana iristeko baliabideak. Baina hori ekitaldi bakoitzeko antolakuntzaren gain gelditu ohi da. Bestalde, ez da inoiz ahaztu behar biztanleriaren heziketa, ikusleak ahalik azkarren has daitezen berpizte-maniobrak egiten, bihotz-biriken geldialdia atzeman orduko (12).

Bat-bateko heriotza, oro har, kirolari helduengan gertatu ohi da gehiago, batez ere lasterketaren azken ekinean. Oinarrian dauden gaitzak, maizenik, arteriosklerosia edo miokardiopatia hipertrofikoa dira, adinak adin. Baina eragile horiek, gehienetan, ez dira ezagunak izaten heriotza gertatu arte. Beraz, garrantzitsua da lasterketa aurreko azterketetan atzematea irregulartasunak. Datuek diotenez, 35 urtetik beherakoetan, sortzetiko gaixotasunak dira prebalenteenak: miokardiopatia hipertrofikoa, miokarditisa, koronarioen anomalia kongenitoak, eskuin-bentrikuluko displasia arritmogenikoa, arritmia gaiztoak eta balbulopatiak. Aldiz, 35 urtetik gorakoek arrisku handiagoa dute kardiopatia iskemikoa izateko; horren eragile izan ohi dira, batez ere, miokardioko infartu akutua, bihotz-enbolia, arteritisa, koronarien disekzioak eta anomalia kongenitoak (13).

Bat-bateko heriotza izandako kirolariek, normalean, aurrez izan dute sintoma iragarleren bat. Baina aintzakotzat hartu ez edo gutxietsi egin dute; eta askotan ez dira jakiten, dela kirolariaren heriotzagatik, dela amnesiagatik. Bada ikerketarik, ordea, sintoma hauek aztertzeko helburuarekin. Horietako batek aztertuak ditu 839 sindrome koronario akutu [SKA]. Hori izandako 430 pazientek (\% 51k) kontatzen dute azken lau asteetan alarma-sintomaren bat izan dutela; \% 80k azken ordubetean eta \% 34k azken 24 orduetan (min torazikoa \% 46k eta disnea \% 18k) (14). Horren harira, funtsezkoa da kirolariei azaltzea zein diren alarma-sintomak eta zeinuak - sinkopea, mareoa, min torazikoa, neurriz kanpoko disnea...-, ariketa fisikoa garaiz utz dezaten, kontsultatu eta, beharrezkoa balitz, azterketa osagarriak egin ditzaten.

Bihotzeko gaitz horietako gehienak susma edo identifika daitezke atsedenean egindako hamabi deribazioko EKG batean (15). Beraz, lasterketa aurreko azterketetan oinarrizkoa da, ohiko datuez gain -historia kliniko, aurrekari familiar eta pertsonal, eta azterketa fisiko-, EKGa ere eskatzea eta hori interpretatzen jakitea. Izan ere, aurreratu dugunez, horrek hainbat berezitasun izan ditzake, 
ariketa fisikoak kirolarien bihotzean eragindako aldaketa fisiologikoen ondorioz. Eta garrantzi handia du EKGa interpretatuko duen medikuak atzematen jakitea zein aldaketa diren kezkagarri. Europako Kardiologia Elkarteak, 2015. urtean aurkeztutako kontsentsuan, garrantzi handikotzat jotzen du EKGa interpretatzerakoan kontuan izatea kirolariaren adina, sexua, arraza, entrenamendu mota eta intentsitatea eta kirol-aurrekariak (16).

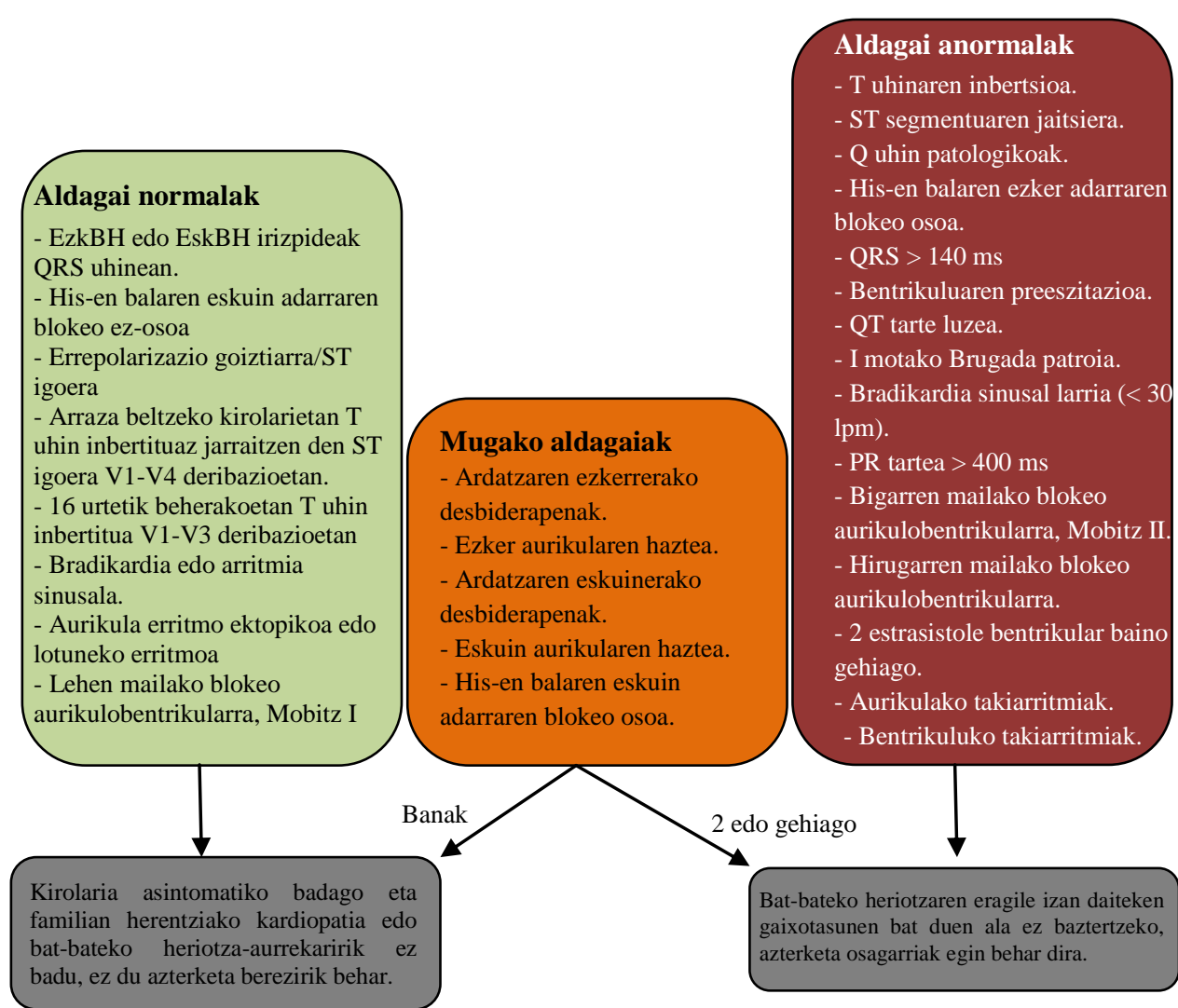

1. irudia. Kirolariaren EKGa interpretatzeko irizpideei buruzko kontsentsu internazionala. EKG: elektrokardiograma. EzkBH: ezker bentrikuloaren hipertrofia. EskBH: eskuin bentrikuloaren hipertrofia.

Irudi horretan biltzen dira zer aldagai ager daitezkeen EKGan, Europako kontsentsuaren arabera.

Baldin eta irregulartasun esanguratsuak aurkitzen bazaizkie kirolariei, ariketa fisikoa behin-behineko etetea gomendatu behar zaie, eta proba osagarriak egitea harik eta kardiopatia estrukturalik ez dagoela baieztatu arte. Ondoren, jarraipen estua egin behar zaie, ikusi baita zenbait gaitz gara ditzakeela horietako \%6k: miokardiopatia hipertrofikoa, eskuin- bentrikuluko miokardiopatia arritmogenikoa, familiako miokardiopatia dilatatua... $(17,18)$.

Baina bihotzeko gaitzen bat izandako zenbait kirolarirekin, ez dago argi zer muga jarri horien ariketa fisikoari. Bana-banako balorazioa egin behar da, kontuan izanda zer gaitz izan duten, horren ondorioak, aldi bereko beste gaitzen bat izan duten, eta hartu beharreko botiken albo-ondorio posibleak. Behin azterketa orokorra eginda, kirolariaren eta medikuaren artean hartuko dira erabakiak.

Ondoren aipatuko ditugu gaitz horietako batzuk:

- Fibrilazio/Flutter aurikularra: historikoki, pertsona helduen gaixotasuna izan da, hipertentsio arterialari lotu zaio eta. Gaur egun, gero eta ohikoagoa da heldu gazteen 
artean (30-40 urte); etengabeko ariketa fisikoak, izan ere, hipertentsio arterialaren ondorioak berdintzen ditu arritmia mota honi dagokionez. Ezinbestekoa da ikerketa sakona egitea ariketa fisikoari berriz ekin aurretik $(19,20)$.

- Wolff-Parkinson-White: gehiegi takikardizatzeko joera duen arritmia. Kirolariak tratamenduaren ondoren -normalean, ikerketa elektrofisiologikoa eta ablazioa eginda - itzul daitezke kirola egitera (21).

- Estrasistolia bentrikularra: gutxitan gertatzen da. Baina baieztatu egin behar da horren oinarrian ez dagoela kardiopatia estrukturalik. Azterketen emaitzak normalak badira, ez dago kirola egiteko mugarik.

- Nodulu barneko birsartzearen ondoriozko takikardia: gehiegizko takikardizazio baten aurrean, gaixotasun honetan pentsatu behar da. Ikerketa elektrofisiologikoa eta ablazioa ere kontuan izan behar dira gaitz honetan.

- Jaiotzetiko QT luzea, takikardia bentrikularra, fibrilazio bentrikularra eta abarretan, ez da gomendatzen ariketa fisikoa egitea, ez badu desfibrilagailu automatikoa ezarria [DAE].

- Balbulopatiak: kirol-praktikak miokardioari lan gehiago eskatzen dionez, lana azkar eta egoki egin behar dute bihotzeko kamerak lotzen dituzten balbulek. Balbula-arazoren bat duen kirolariak - gutxiegitasuna edo estenosia - balorazio zehatza jaso behar du kirola ohiko moduan egin aurretik.

\subsection{Sinkopeak eta kirola}

Alarma-sintoma da kirolariak ariketa fisikoan izandako sinkopea, eta aztertu egin behar da. Izan ere, oso desberdina da kolapsoa ariketa egiten ari direla izatea edo ariketa amaitu ondoren. Azken horiek, normalean, ez dute gaitz larririk adierazten. Ariketa egiten ari direla konortea galtzen dutenek, aldiz, arrazoi larriago bat izan dezakete oinarrian. Kontuan izan behar dira, besteak beste, takikardia bentrikularra, kardiopatia hipertrofikoa, estenosi aortikoa eta sodioaren eta potasioaren alterazioak. Beraz, horrelakoren bat izandako kirolariak harremanetan jarri behar du osasun-profesionalekin, batez ere arrisku bereziko kirola egiten badu -urpekaritza, eskalada, automobilismoa, motoziklismoa- $(22,23)$.

Bada ikerketa bat 16 urteko 7.568 kirolariren datuak biltzen zituena. Atleta horietako 474k (\% 6,2) sinkope bat izana zuten azken 5 urteetan: 411k (\% 87) kirolik egin gabe, 57k (\% 12) kirola egin ondoren eta $6 \mathrm{k}(\% 1)$ kirola egiten ari zirela. Azken horietako batek hipertentsioaren ondoriozko miokardiopatia zuen, beste batek eskuin-bentrikuluko displasia arritmogenikoa eta beste laurak neurokardiogenikoak izan ziren. Ikerketa horrek kirolari guztien jarraipena egin zuen sei urtean: ez zen heriotzarik izan eta sinkopeak \% 2tan errepikatu ziren urteko (24).

Dena den, neuromediatua edo erantzun bagala da kirolarekin erlazionatutako sinkopearen mekanismo fisiologikorik ohikoena, bihotzarekin loturarik ez duena. Ariketa bat-batean etetean gertatzen da, tentsio arterial sistolikoaren erorketa bortitz baten ondorioz agertzen da, barorreflexu mindu baten, basodilatazioaren eta hanketako muskuluen bonba-funtzioa galtzearen ondorio (25, 26). Deshidratazioak eta hipertermiak ere izan dezakete eragina; baita hipogluzemiak, erritmoa igo 
izanak, hipokapniak eta antidepresibo trizikliko edo $\mathrm{H}_{1}$ eta $\mathrm{H}_{2}$ histamina-hartzaileen antagonisten erabilerak ere $(27,28)$.

Normalean, iragankorra eta arina izaten da. Erraz hobetzen da: aho bidezko hidratazioaz, eta etzan eta hankak jasota. Kasu larriagoetarako utzi behar da bena bidezko hidratazioa: hipobolemia-zeinu oso argiak dituztenentzat eta aho bidez likidorik onartzen ez dutenentzat. Aurrerago aztertuko dugu, deshidratazioen atalean.

Kirolariei, hori gerta ez dadin, gomendatzen zaie ariketa bat-batean ez etetea eta, lasterketan zehar, ondo hidratatzea eta odoleko glukosa-mailak kontzentrazio egokietan mantentzea.

\subsection{Digestio-aparatuko gaixotasunak}

Jarduera fisikoak eragindako urdail-hesteetako sintomek eragin handiak izan ditzakete kiroljardueren emaitzetan. Sintoma horiek gehienek jarduera fisikoak gure organismoetan eragindako aldaketa fisiologikoetan dute oinarria. Aldaketa fisiologiko horietako batzuk dira: hesteetako nerbiosisteman asaldurak, hesteetako hormonen jariapenean aldaketak, hesteen odoleztapenaren gutxipena, elikagai eta elektrolitoen xurgapen-prozesuetan aldaketak eta hesteen mugikortasunean aldaketak.

Ikerketa-iturrien arabera, ezberdina da jarduera fisikoak eragindako urdail-hesteetako sintomen intzidentzia: \% 20 eta 96 artean mugitzen da (29). Eta altuagoa da emakumezkoetan eta kirolari gazteetan (30).

Sintoma hauek ezberdinak izan daitezke ariketa motaren arabera. Oro har, distantzia luzeko korrikalariek intzidentzia altuagoa dute urdail-heste sistemako behe-sintometan (inkontinentzia fekala, diarrea, uzki-odoljarioa...) (31). Ultramaratoiko korrikalarietan, aldiz, goragalea izaten da sintoma nagusia (32). Bestalde, $161 \mathrm{~km}$-ko bi ultramaratoi aztertzen zituen ikerketa batek dioenez, goragalea eta gorakoak izan ziren lasterketa ez amaitzeko arrazoirik ohikoenak (\% 23 kasutan) eta amaitu zutenen artean errendimendua jaistearen bigarren arrazoia (33).

Ikus ditzagun, orain, ariketa fisikoaren ondorioz agertzen diren urdail-hesteetako sintoma eta arazo batzuk.

Jarduera fisikoarekin lotutako min abdominal iragankorra. Sabel aldameneko ziztada edo saihets azpiko ziztada moduan ager daiteke. Sintoma hau oso maiz agertzen da kirolarietan. Jarduera fisikoa etetea da tratamendurik eraginkorrena.

Jarduera fisikoak eragindako hesteetako iskemia. Arraroa da (34). Jarduera fisikoan, hesteetako odolfluxua \%50-80an gutxitu daiteke (35). Horren sintomak izaten dira min abdominala, goragalea, gorakoa edo betetasun-sentsazioa. Iskemia horrek eragindako mina ez da aipatu berri dugun "jarduera fisikoarekin lotutako min abdominal iragankorra" bezalakoa. Azken hori baino biziagoa da, ez da hain ongi lokalizatua egoten eta jarduera etenda ez da desagertzen. Hesteetako iskemia daukan pazienteen gehiengoak berez egiten dio aurre hipobolemia-egoera konpontzean.

Goragalea. Korrikalarien \% 6-26an gertatzen da; gorakoak, berriz, korrikalarien \% 2-6an. Nahiz eta jarduera fisikoan gutxi aldatzen den urdaileko azidotasuna, gorakoak eragin ditzake urdailean azido biliarren areagotzeak (36). Sintomak, gehienetan, beren kabuz eta denbora gutxian hobetzen dira, eta oso gutxitan iristen dira asaldura elektrolitikoak eta deshidratazioa eragitera. 
Jarduera fisikoak eragindako beherakoa. Kirolarien \% 14-38an agertzen da (37). Hipotesien arabera, hesteetako mukosak estimulu mekanikoen ondorioz jariapenean asaldurak izaten ditu (38). Uste ohi $\mathrm{da}$, gainera, jarduera fisikoak nerbio-sistema autonomoan eragindako aldaketek eragina dutela heste mehar eta heste lodiaren mugikortasunean. Egon daiteke beste azalpen bat ere: jarduera fisikoak hesteetako mukosaren iragazkortasuna asaldatzen du; eta kalte hori handiagotu egiten du antiinflamatorioak hartzeak (ibuprofenoa, esaterako) (39). Beherakoak, oro har, bere kabuz egiten du onera, eta oso gutxitan eragiten du asaldura elektrolitikoa edo deshidratazioa. Baina 24 orduz luzatzen bada edo beste sintoma batzuk gehitzen bazaizkio - besteak beste, min abdominala, sukarra, odola gorozkietan edo gorakoak - ikerketa sakonagoa egin beharko da. Tratamendu egokiena jardueraren intentsitatea murriztu eta hidratatzea da, aho bidez zein zain barnetik.

Ezkutuko odoljarioa. Maratoiko korrikalarien \% 8-28tan aurkitu da; ultramaratoiko korrikalarien artean, \% 84raino ere irits daiteke. Ageriko odoljarioa ez da oso ohikoa. Kausa nagusia hesteetako iskemia izan daitekeela pentsatu da (40). Jardueraren azelerazioek eta dezelerazioek min mekanikoa sor dezakete hesteetan, eta odol-galera eragin hesteetan barrena. Antiinflamatorio ez-esteroideoak hartzeak (ibuprofenoa, esaterako) handiagotu egin dezake hesteetako mukosaren kaltea, eta erraztu edo areagotu odol-galerak.

Oro har, ezkutuko odoljarioak izaten dituzte kirolariek, eta ez dira ohartzen. Jarduera fisikoak eragindako odoljarioa izan duten eta endoskopia egin zaien kirolari batzuetan, lesio txikiak azaldu dira urdailean eta hesteetan. Lesio horiek, batez ere, gastritis erosiboa, urdaileko ultzera eta kolitis iskemikoa izan dira (41). Anemia oso arraroa izaten da kasu hauetan; eta, agertzekotan, kausa ugari izan ohi ditu (42).

\subsection{Hidratazio-asaldurak eta hiponatremia}

Ultralasterketetan, oso garrantzitsua da ura eta nutrienteak ondo baliatzea. Izerditan, orduko 0,5-2 litroko likido-galera gertatzen da; eta beti da gomendagarria galera horiek aho bidez orekatzea (43). Gehiegizko hidratazioak, ordea, ariketarekin erlazionaturiko hiponatremia ekar dezake; gehienetan asintomatikoa eta arina izaten da, baina kasu batzuetan haren ondorioak heriotzaren arrazoitzat jo izan dira.

Hiponatremia -sodio-asaldura - ez da hain ezohikoa; \%51tik gorako intzidentzia du $161 \mathrm{~km}$-ko ultramaratoietan (44). Horren harira, "drink to thirst" da lasterketetako azken lema; hau da, egarriaren arabera edatea, gehiegizko hidratazioa saihestuz eta pisuaren \% 4-5eko galera onartuz (45).

Deshidratzio-zeinuak dituzten kirolariekin, komeni da aho bidezko hidratazioa baliatzea; zain bidezkoa, berriz, hobe da gordetzea hipobolemia-zeinu larrietarako -kontrolatzen ez den takikardia, azaleko zeinu larriak eta ortostatismoa - eta aho bidez edan ezin dutenentzat $(46,47)$.

Hiponatremiaren tratamendua: sintoma arinak dituztenei, aho bidez egiten saiatuko gara - gatzdun edari hipertonikoak har ditzatela; eta pixa egiten hasi arte, edari isotonikoak edo hipotonikoak ekidin-; entzefalopatiaren sintomak dituztenei, berriz, bena bidez - gatzdun likido hipertonikoen $100 \mathrm{ml}$-ko boloak jarri, emergentzia-zerbitzuak iritsi arte-.

\subsection{Ariketaren ondoriozko errabdomiolisia eta giltzurruneko gutxiegitasun akutua}

Erresistentzia altuko lasterketetan, maiz azaldu ohi da errabdomiolisia (muskuluaren nekrosiaren ondorioz, toxikoak jariatzea odolera). Ultramaratoietako lasterkarietan, ohikoa izaten da $20.000 \mathrm{UI} / \mathrm{I}-$ 
tik gora igotzea kreatin kinasaren maila [kreatin kinasa: muskuluetan jasotzen den entzima bat]; aldi berean, mioglobina garbitzen da giltzurrunean, eta horrek handiagotu egiten du giltzurrungutxiegitasun akutua [GGA] izateko arriskua (48).

Azterketetan ikusi denez, hauek dira GGA gertatzeko arrisku-faktoreak: deshidratazioa, bero-kolpea, aurrez giltzurruneko arazoak izatea, lasterketan zehar antiinflamatorio ez-esteroideoak [AIEE] hartzea, lehiakortasun-maila altua eta entrenamendurik eza $(49,50)$.

Analgesikoak eta antiinflamatorioak direlako erabili ohi dira AIEEak. Baina badituzte albo-ondorioak ere: giltzurruneko odol-fluxua gutxitu dezakete, elektrolitoen mailak aldatu eta azido-baseen trastornoak eragin $(51,52)$. Beraz, iraupen luzeko ariketa fisikoetan, deshidratazio-arriskuagatik, kontu handiz hartu behar dira medikamentu horiek.

Hori dena kontuan harturik, kirolariak mediku batekin kontsultatu beharko du, baldin eta lasterketaren ondorengo 24 orduetan pixa gutxi egin edo hematuria badu; beharrezko proba osagarriak egingo dizkio medikuak eta, beharko balu, tratamendua jarri. Oro har, hidratatzea izango da tratamendua. Dena den, bana-banako tratamendua erabakiko da, larritasunaren eta sodio-mailen arabera.

\subsection{Arnasketa-aparatuko gaixotasunak}

Asma intrintsekoa da kirolari gazteetan agertu ohi den gaixotasunik ohikoena. Baina oso maiz ikusten da ariketak eragindako bronkoespasmoa ere, batik bat arnasbidean hotz-bero kontrastea denean, hasiera 5-15 minutu artean izan daiteke eta kirola amaitu eta ordubetera arte agertu ahal da. Biztanleria orokorrean, \% 10-15ekoa da prebalentzia; eliteko kirolarietan, \% 10-50era arte igo daiteke (53).

Asmarekin erlaziorik ez duten arnasketa-arazoak ere deskribatu dira, behartutako bizi-edukiera (FVC) eta behartutako arnasbeherako bolumena (FEV) konprometitzen dituztenak. Horiek, gehienetan, arnasketa-muskuluen akidurak eraginda gertatzen dira, baina inflamazioaren edo birika-edemaren ondorioz ere gerta daitezke $(54,55)$. Azken hori kontuan hartu beharrekoa da altuera handietako lasterketetan.

Aipamen berezia merezi du ariketak eragindako bronkoespasmoak [AEB]. Honela definitzen da: ariketa fisikoan zehar edo justu hori amaitu berritan agertzen den bronkoespasmoa. Ariketa fisikoa, berez, ez da asma-sortzailea; baizik krisi-abiarazlea, asma dutenetan. Gainera, batzuek diotenez, ariketa fisikoa gutxitzea asmarako arrisku-faktore izan daiteke; ariketa fisikoa egiteak, berriz, asma agertzea ekidin dezake haurretan (56).

Biztanleria orokorrean, ariketak eragindako bronkoespasmoaren prebalentzia \% 5-20 artekoa da; eta asma sintomatikoa duten gaixoen \% 90ek pairatuko du (57). Zenbait ikerketaren arabera, badirudi prebalentzia altuagoa duela eliteko kirolarietan, eta aldakorra kirol motaren arabera. Atenaseko eta Pekingo Joko Olinpikoetan, adibidez, honako kirol hauek izan ziren asmagatik Erabilera Terapeutikoaren Salbuespenarekin lotuenak: igeriketa, txirrindularitza, triatloia, pentatloia eta arrauna; hurrenez hurren honako prebalentzia honekin: igeriketa $\% 18$, txirrindularitza $\% 16$, triatloia $\% 12$, pentatloia $\% 13$, arrauna $\% 7$, gutxi gorabehera. Bestalde, prebalentzia \% 5ekoa baino txikiagoa izan zen erresistentzia-eskaera arinagoa duten kirol-ekintzetan - gimnasia, esgrima eta bela- (58, 59). 
Sintoma ohikoenak arnasestua, bularraldeko ziztadak eta eztula dira; eta ariketa fisikoaren ondorengo orduetan ere iraun dezakete. Diagnostikoa egiteko, batetik, sintomen agerpenak baliatzen dira eta, bestetik, tratamendu bronkodilatadorearen ondoriozko itzulgarritasuna eta $\%$ 10etik gorako hobekuntza-proba.

Dopinaren kontrako Mundu Agentziak (www.wada-ama.org) onartua du, maila batzuen barruan, bronkodilatadoreen erabilera baimen terapeutikorik gabe. Hala ere, hori egiaztatzea gomendatzen da, urtetik urtera aldaketak egon baitaitezke (60).

\subsection{Tenperatura erregulatzeko mekanismoa eta haren asaldurak}

Bero-kolpea eta hipotermia dira tenperaturaren asaldurekin lotura duten gaixotasunik larrienak, lasterketaren ingurunearen arabera.

Gure organismoa gai da berak sortutako beroa kanporatzeko. Lau mekanismo ditu horretarako: izerdi-lurrunketa (hori da nagusia ariketa fisikoan), bero-irradiazioa, kondukzioa eta konbekzioa. Inguruneko tenperatura altua denean, izerdia da funtsezko mekanismoa, nahiz eta beroa galtzeko gaitasun baxua duen (61). Hainbat faktorek eragiten du beroan. Batetik, norbanakoarenak daude: joera pertsonala, atsedenik eza, elkarturiko gaixotasunak, gizentasuna, entrenamendurik eza, aklimataziorik eza...; bestetik, ingurunekoak - tenperatura eta hezetasuna - eta hainbat medikazio edo droga. Saihestu egin behar dira alkohola, anfetaminak edo beste zenbait droga, baita diuretikoak, betablokeatzaileak edo sistema kardiobaskularrerako farmakoak ere. Baldin eta horiek edo antihistaminikoak, antidepresiboak edo litioa bezalakoak hartzen badira, ez da gomendatzen lasterketarik egitea (62).

Deshidratazioak ere badu eragina tenperatura erregulatzeko mekanismoan; jaitsi egiten baitu plasman dagoen bolumena eta zaildu hozte-prozesua. Ikerketa batek dioenez, galtzen den \% 1 bakoitzeko, $0,22{ }^{\circ} \mathrm{C}$ igotzen da tenperatura. Eta, horretaz gain, \% 75ekoa baino handiagoa bada ingurune-hezetasuna, lurrunketa-prozesua ez da eraginkorra (63).

Gorputzeko tenperaturaren arabera, hiru sailetan bereiz ditzakegu beroak eragindako kalteak:

- 38,5-40 ${ }^{\circ} \mathrm{C}$ artean: beroak eragindako akidura. Ez dago eraso neurologikorik, baina ariketa fisikoa egiten jarraitzea zaila da. Tenperatura erregulatzeko mekanismoak mantendu egiten dira, eta gomendagarria da lehenbailehen hidratatzen hastea.

- 40-40,5 ${ }^{\circ} \mathrm{C}$ artean: beroak eragindako lesioa. Organoen lesioak agertzen dira, baina eraso neurologikorik gabe. Maizen kaltetutako organoak muskuluak, giltzurruna eta gibela izaten dira, eta azidosi metabolikoa agertu ohi da.

- $>40,5{ }^{\circ} \mathrm{C}$ : bero-kolpea. Hauxe da egoerarik larriena. Tenperatura erregulatzeko mekanismoek huts egitean agertzen da. Garunari, giltzurrunei, muskuluei eta gibelari erasaten die. Funtsezkoa da hozte azkarra, ondorio larriak edo heriotza ekiditeko. Sintomak desorientazioa, buruko mina, aztoramena, suminkortasuna, konfusioa edo koma izan daitezke.

Bero-kolpea lotuta dago ingurugiroko tenperaturarekin, hezetasun-mailarekin eta lasterketaren erritmoarekin, baina ez pertsonaren hidratazio-maila edo arazo kardiobaskularrekin (64). Egoera fisikoaren hobekuntzak, dena den, beroaren aklimatazioan laguntzen du (65). Beheko taulan ditugu azken urteetako Behobia/San Sebastian 20 km-ko lasterketan egindako artatzeak eta zer eragin izan duen ingurugiroko tenperaturak osasun-arreta kopuruan (66). 
1. taula. Behobia-San Sebastian datuak. Club Deportivo Fortuna (66).

\begin{tabular}{|c|c|c|c|c|c|c|c|}
\hline Data & Parte-hartz. & Izen-emateak & Parte-hartz. \% & $\mathrm{T} \underline{\mathrm{a}}(\mathrm{oC})$ & Hezet. & Haizea & Artatzeak \\
\hline 2007 & 12.683 & 15.068 & $\% 84$ & 11,2 & $\% 71$ & $\mathrm{~N}$ & 82 \\
\hline 2008 & 13.789 & 16.458 & $\% 84$ & 17,7 & $\% 43$ & $S$ & 158 \\
\hline 2009 & 14.877 & 18.500 & $\% 80$ & 11 & $\% 62$ & $70 \mathrm{~km} / \mathrm{h}$ & 71 \\
\hline 2010 & 17.437 & 20.809 & $\% 84$ & 13,3 & $\% 76$ & $25 \mathrm{NW}$ & 85 \\
\hline 2011 & 19.919 & 23.500 & $\% 85$ & 23,5 & $\% 50$ & S & 214 \\
\hline 2012 & 21.533 & 25.581 & $\% 84$ & 10 & $\% 100$ & $50 \mathrm{~km} / \mathrm{h} \mathrm{SW}$ & 60 \\
\hline 2013 & 23.870 & 28.268 & $\% 84$ & 16,1 & $\% 81$ & $>60 \mathrm{~km} / \mathrm{h} \mathrm{SW}$ & 140 \\
\hline 2014 & 26.842 & 30.730 & $\% 87$ & 13 & $\% 68$ & 25 WNW & 154 \\
\hline 2015 & 28.262 & 33.790 & $\% 84$ & 27 & $\% 40$ & $26 \mathrm{~km} / \mathrm{h} \mathrm{S}$ & 445 \\
\hline
\end{tabular}

\subsection{Hezur- eta muskulu-sistemako arazoak}

Gehiegizko erabileraren ondorioz izandako lesioak dira, gehienetan arinak eta atsedenarekin hobetzen direnak. Ultramaratoietan, \% 1-24 artean gertatu ohi dira (67). Diagnostiko ohikoena min femoropatelarra da (\% 7-33), Akilesen tendoiaren tendinitisa (\% 8-19) eta banda iliotibialaren sindromea (\% 7). Gehien mindutako artikulazioak, berriz, belaunak, orkatilak eta aldaka dira. Guztien tratamendua, oro har, izotza, ariketaren moldaera, mina arintzeko farmakoak eta luzaketak egitea izaten da. Baina lasterketan batez ere taping-ak, luzaketak eta masajeak izan daitezke eraginkorrenak (68). Dena den, nahiz eta ez izan kirolariaren gustukoena, atsedena da lesio mota horiek guztiek behar duten tratamendua.

Nahiz eta tratamendu egokia hartu, lesioak irauten badu, kontuan izan behar dira estres-hausturak. Indar arineko kolpe errepikakorrek eraginak izaten dira, normalean beheko gorputz-adarretan. Are eta ohikoagoak dira osteoporosia edo bitamina-gutxiegitasuna duten kirolariengan (69); beraz, susmo-maila handiagoa izan behar da kirolari horiekin.

\subsection{Babak eta azaleko beste zenbait arazo}

Lasterketa mota hauetan, babak dira atentzio medikoa behar duten kalterik ohikoenak: \% 17-40 artean ultramaratoietan (70). Zorionez, gehienak ez dira gaiztotzen, eta \%5ek soilik izango du zelulitisa bezalako konplikazioren bat (71). Dena den, oso mingarriak izan ohi dira, eta zerikusia izaten dute lasterketaren errendimenduan. Gomendagarria da babak drainatzea, betiere gaineko azala mantenduz. Baina kontu handia izan behar da odoletan dauden babekin, infektatzeko arrisku handiagoa dute eta.

Ohikoak dira azkazal azpiko hematomak ere: \% 3-10 korrikalarietan gertatzen dira; mingarriak direnean, gomendagarria da azkazala zulatuz drainatzea, dela esterilizatutako orratz batekin, dela aurrez berotutako klip batekin (72).

Korrikalarien \% 9an agertuko dira urradurak, batez ere izter-barrenetan, bizkarrean edo titiburuetan. Lubrifikazio edo taping bidez ekidin daitezke, eta tratamendua ere modu berean egin daiteke. 
Nahiz eta korrikalariak prestatuak egon azal-asaldura horiek denak ekiditeko eta tratatzeko, babak izaten dira lasterketa mota hauetan atentzio medikoen arrazoirik ohikoena.

\section{Ehunmilak Ultra-Trail 2017ko artatzeak}

Aurreratu dugunez, artikulu honen asmoetako bat da 2017ko Ehunmilak lasterketan emandako atentzioak aztertzea. Honako taulan laburbiltzen dira 368 atentzioen zergatiak. Gehienak larritasun baxukoak izan ziren; babak izan ziren ohikoenak, gero hezur-muskuluetako minak.

Baina ospitalera eraman behar izan ziren korrikalarietatik bi Zainketa Intentsiboetako Unitatean (ZIU) zaindu zituzten. Bat hil egin zen.

2. taula. Ehunmilak Ultra-Trail 2017ko artatzeak

\begin{tabular}{|c|c|c|c|}
\hline \multicolumn{4}{|c|}{ Ehunmilak Ultra-Trail 2017ko artatzeak } \\
\hline \multicolumn{2}{|l|}{ GUZTIRA } & 368 & Ospitalera bidaliak $12\left({ }^{*}\right)$ \\
\hline \multirow{2}{*}{$\begin{array}{l}\text { Gertaera } \\
\text { kardiobaskularrak }\end{array}$} & BBG & 1 & Heriotza $(*)$ \\
\hline & $\begin{array}{l}\text { Biriketako edema } \\
\text { akutua }\end{array}$ & 1 & ZIU $(*)$ \\
\hline \multicolumn{2}{|l|}{ Sinkopea } & 3 & $\begin{array}{l}\text { Bat ospitalera bidali zen }\left({ }^{*}\right) \text {, beste } \\
\text { biak baso-bagalak izan ziren }\end{array}$ \\
\hline \multicolumn{2}{|l|}{ Zorabioa } & 26 & $\begin{array}{l}\text { Deshidratazioak, nekea, hipotentsioa } \\
\left({ }^{*}\right)\end{array}$ \\
\hline \multicolumn{2}{|l|}{ Hipogluzemia } & 2 & Ez diabetikoak \\
\hline \multirow{3}{*}{$\begin{array}{l}\text { Digestio aparatuko } \\
\text { gaitzak }\end{array}$} & Min abdominala & 2 & Automugatuak \\
\hline & Goragalea & 2 & Aho bidez onartu zuten \\
\hline & Gorakoa & 1 & Aho bidez onartu zuten \\
\hline \multicolumn{2}{|l|}{ Deshidratazioa } & 1 & Seroterapia behar izan zuen $\left({ }^{*}\right)$ \\
\hline \multicolumn{2}{|l|}{ Arnas aparatuko gaitzak } & 1 & Bronkoespamoa. Asma \\
\hline \multicolumn{2}{|c|}{ Min toraziko pleuritikoa } & 1 & \\
\hline \multirow[t]{2}{*}{ Tenperatura-arazoak } & Hipotermia & 2 & Lasterketa utzi zuten \\
\hline & Hipertermia & 3 & Lasterketa amaitzean \\
\hline \multirow{2}{*}{$\begin{array}{l}\text { Hezur-muskuluetako } \\
\text { minak }\end{array}$} & Zuzenekoak & 16 & Hausturarik gabe $(* 3)$ \\
\hline & Ez-zuzenekoak & 117 & Gainkargak $\left({ }^{*} 2\right)$ \\
\hline \multicolumn{2}{|l|}{ Babak } & 137 & \\
\hline \multirow{5}{*}{$\begin{array}{l}\text { Azaleko beste arazo } \\
\text { batzuk }\end{array}$} & Zauriak & 31 & \\
\hline & Urradurak & 30 & \\
\hline & Flebitisa & 1 & Ospitalera bidali zen $\left({ }^{*}\right)$ \\
\hline & Zelulitisa & 1 & Ospitalera bidali zen $\left({ }^{*}\right)$ \\
\hline & Hemorroideak & 1 & Lasterketa utzi zuen \\
\hline
\end{tabular}

Maratoiko 52 urteko korrikalari batek konortea galdu zuen 27. kilometroan. Bertan zeuden Gurutz Gorriko teknikariek berehala hasi zituzten oinarrizko bihotz-biriketako berpizte [BBB] lanak. Medikuak eta erizainak iritsi eta, BBB aurreratua egin ondoren, berpiztea lortu zuten. Baina egun batzuen buruan hil zen Donostiako Ospitalean, Zainketa Intentsiboetako Unitatean [ZIU].

Biriketako edema akutua izandako korrikalariak ere ZIUn egin zituen egun batzuk. Lasterketako 160. kilometroan zihoala, neurriz kanpoko nekea atzeman zioten. Azterketa guztiak egin ondoren, ez 
zioten aparteko larritasunik ikusi. Zirkulazio-aparatuan eta arnas aparatuan ez zioten patologiarik aurkitu. Odol-analisietan ez zen asaldura hidroelektrikorik topatu. ZIUko medikuen ustez, gorputzak ordu askotan jasandako bihotz-maiztasun altuak eta tentsio arterial altuak eragingo zioten nekea.

Guztira, hiru korrikalari artatu ziren sinkopearen ondorioz. Hirurek zituzten jatorri baso-bagaleko konorte-galeraren ezaugarriak. Beren onera etorri ziren bi, oinarrizko neurriekin eta zainetiko seroterapiaren ondoren. Hirugarrenak, ordea, hiru konorte-galera izan zituen, nahiz eta tratamendua jaso. Wolf-Parkinson-White motako asaldura elektrokardiografikoa zuen korrikalaria izanagatik, horrek ez zuen aparteko arazorik sortu. Hala ere, hiru egun egin zituen ospitalean, alta medikoa jaso arte.

Beste bi korrilakari, berriz, flebitisaren eta zelulitisaren ondorioz eraman zituzten ospitalera. Batek, tibia aurreko giharreko gainkarga nabarmena zuen lasterketa aurreko egunetatik. Lasterketa utzi behar izan zuen 50. kilometroan, hantura eta eritema nabarmenak sortzen zizkion oinazeagatik. Besteak, zelulitisa zuen izter-barnealdean, eta sukarra eta oinaze nabarmenak zituen 80. kilometroan. Ustez, lasterketa aurreko egunetan moztutako ileek sortutako folikulitisa zuen gaitzaren eragilea.

Ehumilak Ultra-Trailaren 8. edizio hura ez zen bereziki gogorra izan klimatologiaren aldetik. Baina, ohikoa denez, zenbait kontsulta izan ziren zorabioek eraginda. Antzekoak ia denak: hipotentsioa, ondoeza, nekea, sukar pixkaren bat. la denek nahikoa izan zuten oinarrizko tratamendua. Baina batzuek seroterapia behar izan zuten. Korrikalari bakarra izan zen $1.000 \mathrm{ml}$-ko seroterapia hartuta ere errekuperatu ez zena. Ospitalera bidali zuten. Ordu gutxi barru jaso zuen alta-txostena.

Iraupen luzeko oinezko lasteketa izanik, oinek eta hankek jasan zituzten ondoriorik gehienak. Askok erorketa txikiak izan zituzten; beste batzuek bihurrituak eta giharretako gainkargak; bakarren batek zuntz-hausturaren bat... Batek oinazeak izan zituen, lehendik ebakuntza jasandako oinean. Batzuk ospitalera bideratuak izan ziren proba osagarriak egitera. Dena den, inork ez zuen hezur-hausturarik izan.

Tenperatura-asaldurei dagokienez, hipotermia arina izan zuten bi lasterkarik, gauez atsedena hartzera geratu eta berriz laskerta hasteko modura jarri ezinda. Behin lasterketa amaituta, hiru korrikalarik eskatu zuten asistentzia hipertermiagatik: $>38{ }^{\circ} \mathrm{C}$. Oinarrizko tratamendua jasota errekuperatu ziren, larritasun-zantzurik azaldu gabe.

\section{Ondorioak eta eztabaida}

Argi dago: erronka handia dira iraupen luzeko lasterketak. Hasteko, korrikalarientzat; baina baita antolatzaileentzat eta osasun-arreta osatzen duten lantaldeentzat ere. Izan ere, nahiz eta ondo prestatutako kirolariek parte hartu oro har, edozein ustekabeko gerta daiteke. Eritasun arinak dira ohikoenak. Baina ager daitezke heriotza eragin dezaketen patologiak ere. Mendi-lasterketak direnez, arazo nabarmena da irisgarritasuna. Gauez korrika egiteak areagotu egiten du zailtasuna. Segurtasun-neurriak, geo-lokalizatzaileak, boluntarioak, osasun-arretako logistika... Dimentsio handiko kirol-ekitaldiak dira, eta maila egokiko antolakutza-sistema eskatzen dute ezinbestez. Batzuetan, hala ere, baliteke nahikoa ez izatea. Irabaziko ahal dugu!

\section{Bibliografia}


1. Hoffman MD, Ong JC, Wang G. Historical analysis of participation in $161 \mathrm{~km}$ ultramarathons in North America. Int J Hist Sport. 2010;27 (11):1877-91.

2. 2013 Year in review \& ultrarunners of the year. [Internet]. UltraRunning. 2014 Urt/Ots; [Kontsulta 2019-2-20]; 30-47. Eskuragarri: https://issuu.com/ultrarunningmag/docs/ian-feb2014

3. Hoffman MD, Pasternak A, Rogers IR, Khodaee M, Hill JC, Townes DA, Scheer BV, Krabak BJ, Basset P, Lipman GS. Medical Services at Ultra-Endurance Foot Races in Remote Environments: Medical Issues and Consensus Guidelines. Sports Med. 2014; 44 (8): 10551069.

4. Hammond-Haley M, Patel RS, Providência R, Lambiase PD. Exercise restrictions for patients with inherited cardiac conditions: Current guidelines, challenges and limitations. Int J Cardiol. 2016 Api 15;209:234-41.

5. Yeo TJ, Sharma S. Using the 12-Lead Electrocardiogram in the Care of Athletic Patients. Cardiol Clin. 2016 Aza;34(4):543-555.

6. Vuori I. The cardiovascular risks of physical activity. Acta Med Scand Suppl. 1986;711:205214.

7. Kim JH, Malhotra R, Chiampas G, d'Hemecourt P, Troyanos C, Cianca J, Smith RN, Wang TJ, Roberts WO, Thompson PD, Baggish AL; Race Associated Cardiac Arrest Event Registry (RACER) Study Group. Cardiac arrest during long-distance running races. New Engl J Med. 2012;366(2):130-140.

8. Webner D, DuPrey KM, Drezner JA, Cronholm P, Roberts WO. Sudden cardiac arrest and death in United States marathons. Med Sci Sports Exerc. 2012;44(10):1843-1845.

9. Harris KM, Henry JT, Rohman E, Haas TS, Maron BJ. Sudden death during the triathlon. JAMA. 2010 Api 7;303(13):1255-7

10. Zipes DP, Ackerman MJ, Estes NA 3rd, Grant AO, Myerburg RJ, Van Hare G. Task Force 7: arrhythmias. J Am Coll Cardiol. 2005 Api 19;45(8):1354-63.

11. Resuscitation Council (UK) [Internet]. Resuscitation guidelines 2010 [Kontsulta 2019/06/19]. Eskuragarri: http://www.resus.org.uk/pages/guide.htm.

12. Hillis WS, McIntyre PD, Maclean J, Goodwin JF, McKenna WJ. ABC of sports medicine. Sudden death in sport. BMJ. 1994 Ira 10;309(6955):657-60

13. Van Camp SP, Bloor CM, Mueller FO, Cantu RC, Olson HG.Nontraumatic sports death in high school and college athletes. Med Sci Sports Exerc. 1995 Mai;27(5):641-7

14. Marijon E, Uy-Evanado A, Dumas F, Karam N, Reinier K, Teodorescu C, Narayanan K, Gunson K, Jui J, Jouven X, Chugh SS. Warning Symptoms Are Associated With Survival From Sudden Cardiac Arrest. Ann Intern Med. 2016 Urt 5;164(1):23-9.

15. Sharma S, Drezner JA, Baggish A, Papadakis M, Wilson MG, Prutkin JM, La Gerche A, Ackerman MJ, Borjesson M, Salerno JC, Asif IM, Owens DS, Chung EH, Emery MS, Froelicher VF, Heidbuchel H, Adamuz C, Asplund CA, Cohen G, Harmon KG, Marek JC, Molossi S, Niebauer J, Pelto HF, Perez MV, Riding NR, Saarel T, Schmied CM, Shipon DM, Stein R, Vetter VL, Pelliccia A, Corrado D. International Recommendations for Electrocardiographic Interpretation in Athletes. J Am Coll Cardiol. 2017 Ots 28;69(8):1057-1075.

16. Sharma S, Drezner JA, Baggish A, Papadakis M, Wilson MG, Prutkin JM, La Gerche A, Ackerman MJ, Borjesson M, Salerno JC, Asif IM, Owens DS, Chung EH, Emery MS, Froelicher VF, Heidbuchel H, Adamuz C, Asplund CA, Cohen G, Harmon KG, Marek JC, Molossi S, Niebauer J, Pelto HF, Perez MV, Riding NR, Saarel T, Schmied CM, Shipon DM, Stein R, Vetter 
VL, Pelliccia A, Corrado D. International Recommendations for Electrocardiographic Interpretation in Athletes. J Am Coll Cardiol. 2017 Ots 28;69(8):1057-1075.

17. Kim JH, Noseworthy PA, McCarty D, Yared K, Weiner R, Wang F, Wood MJ, Hutter AM, Picard $\mathrm{MH}$, Baggish AL. Significance of electrocardiographic right bundle branch block in trained athletes. Am J Cardiol. 2011 Api 1;107(7):1083-9.

18. Viskin S, Rosovski U, Sands AJ, Chen E, Kistler PM, Kalman JM, Rodriguez Chavez L, Iturralde Torres P, Cruz F FE, Centurión OA, Fujiki A, Maury P, Chen X, Krahn AD, Roithinger F, Zhang L, Vincent GM, Zeltser D. Inaccurate electrocardiographic interpretation of long QT: the majority of physicians cannot recognize a long QT when they see one. Heart Rhythm. 2005 Eka;2(6):569-74.

19. Talan DA, Bauernfeind RA, Ashley WW, Kanakis C Jr, Rosen KM. Twenty-four hour continuous ECG recordings in long-distance runners. Chest. 1982 Uzt;82(1):19-24.

20. Stein R, Medeiros CM, Rosito GA, Zimerman LI, Ribeiro JP. Intrinsic sinus and atrioventricular node electrophysiologic adaptations in endurance athletes. J Am Coll Cardiol. 2002 Mar 20;39(6):1033-8.

21. Munger TM, Packer DL, Hammill SC, Feldman BJ, Bailey KR, Ballard DJ, Holmes DR Jr, Gersh BJ. A population study of the natural history of Wolff-Parkinson-White syndrome in Olmsted County, Minnesota, 1953-1989. Circulation. 1993 Mar;87(3):866-73.

22. Calkins $H$, Seifert $M$, Morady F. Clinical presentation and long-term follow-up of athletes with exercise-induced vasodepressor syncope. Am Heart J. 1995 Eka;129(6):1159-64.

23. Colivicchi F, Ammirati F, Biffi A, Verdile L, Pelliccia A, Santini M.Exercise-related syncope in young competitive athletes without evidence of structural heart disease. Clinical presentation and long-term outcome. Eur Heart J. 2002 Uzt;23(14):1125-30.

24. Colivicchi F, Ammirati F, Santini M. Epidemiology and prognostic implications of syncope in young competing athletes. Eur Heart J. 2004 Urr;25(19):1749-53.

25. Speedy DB, Noakes TD, Holtzhausen LM. Exercise-associated collapse: postural hypotension, or something deadlier? Phys Sportsmed. 2003 Mar;31(3):23-9.

26. Holtzhausen LM, Noakes TD. The prevalence and significance of post-exercise (postural) hypotension in ultramarathon runners. Med Sci Sports Exerc. 1995 Abe;27(12):1595-601.

27. Asplund CA, O'Connor FG, Noakes TD. Exercise-associated collapse: an evidence-based review and primer for clinicians. Br J Sports Med. 2011 Aza;45(14):1157-62.

28. Sakaguchi S, Shultz JJ, Remole SC, Adler SW, Lurie KG, Benditt DG. Syncope associated with exercise, a manifestation of neurally mediated syncope. Am J Cardiol. 1995 Mar 1;75(7):47681.

29. Riddoch C, Trinick T. Gastrointestinal disturbances in marathon runners. Br J Sports Med. 1988 Eka;22(2):71-4.

30. ter Steege RW, Kolkman JJ. Review article: the pathophysiology and management of gastrointestinal symptoms during physical exercise, and the role of splanchnic blood flow. Aliment Pharmacol Ther. 2012 Mar;35(5):516-28.

31. Sullivan SN. Exercise-associated symptoms in triathletes. Phys Sportsmed 1987; 15:105-108.

32. Stuempfle KJ, Hoffman MD. Gastrointestinal distress is common during a $161-\mathrm{km}$ ultramarathon. J Sports Sci. 2015;33(17):1814-21.

33. Hoffman MD, Fogard K. Factors related to successful completion of a 161-km ultramarathon. Int J Sports Physiol Perform. 2011 Mar;6(1):25-37.

34. Beaumont AC, Teare JP. Subtotal colectomy following marathon running in a female patient. J R Soc Med. 1991 Uzt;84(7):439-40. 
35. Clausen JP. Effect of physical training on cardiovascular adjustments to exercise in man. Physiol Rev. 1977 Urr;57(4):779-815.

36. Moses FM. The effect of exercise on the gastrointestinal tract. Sports Med. 1990 Mar;9(3):159-72.

37. Keeffe EB, Lowe DK, Goss JR, Wayne R. Gastrointestinal symptoms of marathon runners. West J Med. 1984 Urr;141(4):481-4.

38. Oektedalen O, Flaten O, Opstad PK, Myren J. hPP and gastrin response to a liquid meal and oral glucose during prolonged severe exercise, caloric deficit, and sleep deprivation. Scand J Gastroenterol. 1982 Abu;17(5):619-24.

39. Pals KL, Chang RT, Ryan AJ, Gisolfi CV. Effect of running intensity on intestinal permeability. J Appl Physiol (1985). 1997 Ots;82(2):571-6.

40. Stewart JG, Ahlquist DA, McGill DB, Ilstrup DM, Schwartz S, Owen RA. Gastrointestinal blood loss and anemia in runners. Ann Intern Med. 1984 Eka;100(6):843-5.

41. Schwartz AE, Vanagunas A, Kamel PL. Endoscopy to evaluate gastrointestinal bleeding in marathon runners. Ann Intern Med. 1990 Urr 15;113(8):632-3.

42. Brotherhood J, Brozović B, Pugh LG. Haematological status of middle and long-distance runners. Clin Sci Mol Med 1975; 48:139-45.

43. American College of Sports Medicine, Sawka MN, Burke LM, Eichner ER, Maughan RJ, Montain SJ, Stachenfeld NS. American College of Sports Medicine position stand. Exercise and fluid replacement. Med Sci Sports Exerc. 2007 Ots;39(2):377-90.

44. Hoffman MD, Hew-Butler T, Stuempfle KJ. Exercise-associated hyponatremia and hydration status in 161-km ultramarathoners. Med Sci Sports Exerc. 2013 Api;45(4):784-91.

45. Bennett BL, Hew-Butler T, Hoffman MD, Rogers IR, Rosner MH; Wilderness Medical Society. Wilderness Medical Society practice guidelines for treatment of exercise-associated hyponatremia. Wilderness Environ Med. 2013 Sep;24(3):228-40. doi: 10.1016/j.wem.2013.01.011. Epub 2013 Apr 13. Erratum in: Wilderness Environ Med. 2014 Mar;25(1):129.

46. Kenefick RW, O'Moore KM, Mahood NV, Castellani JW. Rapid IV versus oral rehydration: responses to subsequent exercise heat stress. Med Sci Sports Exerc. 2006 Abe;38(12):212531.

47. van Rosendal SP, Osborne MA, Fassett RG, Lancashire B, Coombes JS. Intravenous versus oral rehydration in athletes. Sports Med. 2010 Api 1;40(4):327-46.

48. Hoffman MD, Ingwerson JL, Rogers IR, Hew-Butler T, Stuempfle KJ. Increasing creatine kinase concentrations at the 161-km Western States Endurance Run. Wilderness Environ Med. 2012 Mar;23(1):56-60.

49. Bruso JR, Hoffman MD, Rogers IR, Lee L, Towle G, Hew-Butler T. Rhabdomyolysis and hyponatremia: a cluster of five cases at the 161-km 2009 Western States Endurance Run. Wilderness Environ Med. 2010 Abe;21(4):303-8.

50. Clarkson PM. Exertional rhabdomyolysis and acute renal failure in marathon runners. Sports Med. 2007;37(4-5):361-3.

51. Whelton A. Nephrotoxicity of nonsteroidal anti-inflammatory drugs: physiologic foundations and clinical implications. Am J Med. 1999 Mai 31;106(5B):13S-24S.

52. Schneider V, Lévesque LE, Zhang B, Hutchinson T, Brophy JM. Association of selective and conventional nonsteroidal antiinflammatory drugs with acute renal failure: A populationbased, nested case-control analysis. Am J Epidemiol. 2006 Aza 1;164(9):881-9. 
53. Sonna LA, Angel KC, Sharp MA, Knapik JJ, Patton JF, Lilly CM. The prevalence of exerciseinduced bronchospasm among US Army recruits and its effects on physical performance. Chest. 2001 Eka;119(6):1676-84.

54. Mahler DA, Loke J. Pulmonary dysfunction in ultramarathon runners. Yale J Biol Med. 1981;54:243-8.

55. Rogers IR, Inglis S, Speedy D, Hillman D, Noffsinger B, Jacobs I. Changes in respiratory function during a wilderness multisport endurance competition. Wilderness Environ Med. 2001;12:13-16.

56. Storms WW. Asthma associated with exercise. Immunol Allergy Clin North Am. 2005 Ots;25(1):31-43.

57. Mountjoy M, Fitch K, Boulet LP, Bougault V, van Mechelen W, Verhagen E. Prevalence and characteristics of asthma in the aquatic disciplines. J Allergy Clin Immunol. 2015 Ira;136(3):588-94.

58. Bougault V, Turmel J, Boulet LP. Bronchial challenges and respiratory symptoms in elite swimmers and winter sport athletes: Airway hyperresponsiveness in asthma: its measurement and clinical significance. Chest. 2010 Abu;138(2 Suppl):31S-37S.

59. The International Olympic Committee (IOC) Consensus Statement on Periodic Health Evaluation of Elite Athletes: March 2009. Journal of Athletic Training: Sep/Oct 2009, 44, 538557

60. AEPSAD [Internet] BOE. Núm. 6. 2017/1/7 [Kontsulta: 2019/06/19]; Sec. I. Pág. 770. Eskuragarri:

http://www.aepsad.gob.es/aepsad/dms/microsites/aepsad/actualidad/noticias/2017/listade-sustancias-dopantesBOE2017/lista\%20de\%20sustancias\%20dopantes\%20BOE\%202017.pdf

61. Sawka MN, Young AJ, Francesconi RP, Muza SR, Pandolf KB. Thermoregulatory and blood responses during exercise at graded hypohydration levels. J Appl Physiol (1985). 1985 Aza;59(5):1394-401.

62. Epstein Y. Heat intolerance: predisposing factor or residual injury? Med Sci Sports Exerc. 1990 Ots;22(1):29-35.

63. Montain SJ, Coyle EF. Influence of graded dehydration on hyperthermia and cardiovascular drift during exercise. J Appl Physiol (1985). 1992 Oct;73(4):1340-50.

64. Bouchama A, Knochel JP. Heat stroke. N Engl J Med. 2002 Eka 20;346(25):1978-88.

65. Nybo L, Rasmussen P, Sawka MN. Performance in the heat-physiological factors of importance for hyperthermia-induced fatigue. Compr Physiol. 2014 Api;4(2):657-89.

66. Esnal H. Archivo personal

67. Khodaee M, Ansari M. Common ultramarathon injuries and illnesses: race day management. Curr Sports Med Rep. 2012 Nov-Abe;11(6):290-7.

68. Lopes AD, Hespanhol Júnior LC, Yeung SS, Costa LO. What are the main running-related musculoskeletal injuries? A Systematic Review. Sports Med. 2012 Urr 1;42(10):891-905.

69. Saunier J, Chapurlat R. Stress fracture in athletes. Joint Bone Spine. 2018 Mai;85(3):307-310.

70. Hoffman MD, Fogard K. Factors related to successful completion of a 161-km ultramarathon. Int J Sports Physiol Perform. 2011 Mar;6(1):25-37.

71. Krabak BJ, Waite B, Schiff MA. Study of injury and illness rates in multiday ultramarathon runners. Med Sci Sports Exerc. 2011 Abe;43(12):2314-20.

72. Scheer BV, Murray A. Al Andalus Ultra Trail: an observation of medical interventions during a 219-km, 5-day ultramarathon stage race. Clin J Sport Med. 2011 Sep;21(5):444-6. 